\title{
Soroprevalência de anticorpos contra o sarampo de uma determinada população infantil de Botucatu, SP
}

\author{
A seroprevalence of measles antibodies of a children population \\ of Botucatu, São Paulo State, Brazil
}

Ilda de Godoy e Domingos Alves Meira

\begin{abstract}
Resumo Esta pesquisa trata-se de um estudo de soroprevalência de anticorpos contra o sarampo, de uma determinada população infantil residente em Botucatu, SP, com o objetivo de avaliar o estado imunólogico, induzido quer por infecção natural, quer por meio de vacinação. Foram estudadas 101 crianças, sendo que todas receberam a vacina contra o sarampo. Os exames laboratoriais utilizados para avaliar a presença de anticorpos, nas amostras de sangue coletadas, foram o teste de Inibição de Hemaglutinação (IH) e o Ensaio imunoenzimático (ELISA). Os resultados do teste de $\mathrm{IH}$, mostraram que 92,1\% das amostras apresentavam anticorpos contra o sarampo. As amostras com títulos < que 1:4, quando estudadas pela $\mathrm{IH}$, foram retestadas no mesmo laboratório por meio do ELISA, e somente duas mantiveram-se negativas para anticorpos contra o sarampo. Portanto, em 98\% das amostras de soro das crianças estudadas os anticorpos contra o sarampo estavam presentes.
\end{abstract}

Palavras-chaves: Sarampo. Soroprevalência. Vacina.

Abstract A study of the seroprevalence of measles antibodies was conducted in a population of children residing in Botucatu, SP, in order to asses their immunological status whether induced by natural infection or by vaccination. A total of 101 children were studied, all of which had been vaccinated against measles. The laboratory tests used to determine the presence of antibodies in the collected blood samples were hemagglutination inhibition (HI) and immunoenzymatic assay (ELISA). HI results showed that $92.1 \%$ of the samples presented antibodies against measles. Samples with titers $<1: 4$ when studied by HI were retested by ELISA in the same laboratory and only two continued to be negative for measles antibodies. Thus, measles antibodies were present in $98 \%$ of the serum samples from the children studied.

Key-words: Measles. Vaccine. Seroprevalence.

O sarampo é uma doença infecciosa viral, que, durante muitos séculos, foi considerada como uma forma menos grave de varíola pelas populações mais antigas ${ }^{310}$.

A imunidade resultante da infecção pelo vírus do sarampo é duradoura, sendo raro encontrar na literatura dados relatados de recidiva ${ }^{27}$.
O desenvolvimento de uma vacina de vírus vivo atenuado do sarampo, efetiva e eficaz, tornou possível a erradicação da doença. Entretanto, um dos problemas que ainda permanece é o desconhecimento da duração da imunidade entre os vacinados ${ }^{20}$. Uma vez que o sarampo natural produz imunidade duradoura

Curso de Pós-graduação em Doenças Tropicais e Curso de Graduação em Enfermagem da Faculdade de Medicina de Botucatu da Universidade Estadual Paulista, Botucatu, SP, Brasil.

Endereço para correspondência: Profa Ilda de Godoy. Curso de Graduação em Enfermagem/UNESP. Rubião Júnior, 18618-970 Botucatu, SP, Brasil.

Tel: 5514 6802-6004/6070; fax: 5514 6821-3452.

e-mail degodoy@fmb/unesp.br

Recebido para publicação em 29 /10/98 
para doença subseqüente, é importante que a vacina também confira este tipo de imunidade. Se isto não ocorrer, indivíduos que foram imunizados precocemente podem tornar-se suscetíveis à doença quando adultos ${ }^{20}$.

Trabalhos sobre a eficácia da vacinação, desenvolvidos em várias regiões, tomou-se como norma a aplicação da vacina aos nove meses de idade ${ }^{24} 26$. Com essa conduta, cerca de 5 a $10 \%$ das crianças não respondem com soroconversão. Por outro lado, se a vacinação, no Brasil, fosse retardada até os 15 meses de idade, como é a rotina seguida nos países desenvolvidos, 30\% ou mais já teriam adquirido o sarampo, e muitas delas poderiam ter morrido ${ }^{34}$.

Considerando-se que depois da doença instalada, muito pouco pode ser feito para evitar a sua evolução e conseqüentes complicações, a imunização é a medida mais eficaz na proteção contra o sarampo.

A sorologia do sarampo tem sido rotineiramente realizada pelo teste de $\mathrm{IH}$, considerado como um ensaio adequado para determinar o estado imune ${ }^{17}$. Entretanto, estudos mostraram que o teste de $\mathrm{IH}$, é menos sensível quando comparado ao ELISA e o de Neutralização em Placa (RNP), os quais aparentemente tem sensibilidade semelhante ${ }^{52528}$.

Este presente estudo foi desenvolvido para conhecer o estado imunológico, em relação ao sarampo, induzido quer pela infecção natural pelo vírus, quer pela vacinação de uma determinada população infantil.

\section{MATERIAL E MÉTODOS}

O estudo compreendeu a observação de 101 crianças dentre as inscritas no Programa de Imunização do Centro de Saúde Escola (CSE), ligado à Faculdade de Medicina de Botucatu, São Paulo, Brasil, nascidas no período compreendido entre 1989 e 1991, que compareceram ao serviço em resposta à carta convite.

À mãe ou responsável legal era explicado o objetivo, a metodologia da pesquisa e somente com o consentimento dos mesmos as crianças participavam do estudo.

De acordo com esse critério, foram selecionadas as crianças incluídas para o estudo do comportamento dos títulos de anticorpos contra o sarampo. Nessa pesquisa foram consideradas as seguintes variáveis: sexo, número de doses de vacina recebidas, idade em que as mesmas foram aplicadas, e presença ou não de história de sarampo no passado; e uma ficha padrão foi utilizada para coleta de dados da criança.

Amostras sangüíneas foram coletadas de todas as crianças participantes do estudo, por flebopunção. O sangue coletado foi encaminhado ao laboratório para centrifugação e o soro foi estocado em freezer a $-20^{\circ} \mathrm{C}$ até a realização dos testes. Em seguida, as amostras foram encaminhadas para o Laboratório I de Sorocaba - Instituto Adolfo Lutz, por ser este Centro de Referência para pesquisa de anticorpos contra - Sarampo do Centro de Vigilância Epidemiológica da Secretária de Saúde do Estado de São Paulo, para a realização do teste de IH para o sarampo ${ }^{29}$. As amostras de soro negativas pela IH foram submetidas, nesse mesmo laboratório, a detecção de anticorpos classe IgG por meio do ELISA 4151635 .

O projeto de estudo foi aprovado pela Comissão de Ética de Enfermagem do Hospital de Clínicas da Faculdade de Medicina de Botucatu.

Estudo laboratorial. Reação de inibição de hemaglutinação ${ }^{28}$. Realizado segundo procedimento padrão do Laboratório. Consideraramse como negativos todos os soros que apresentaram títulos de $\mathrm{IH}<1: 4$.

Detecção de anticorpos da classe IgG contra o sarampo por meio do ensaio imunoenzimático ${ }^{15} 1635$. Para realização dos testes foi utilizado um Kit comercial (Kit Enzynost Measles $\AA$, Berhingwereke AG). Na realização dos testes foram seguidas rigorosamente as orientações do fabricante.

\section{RESULTADOS}

Característica da casuística. Cento e uma crianças participaram desse estudo, sendo que $50 \%$ do sexo feminino e $50 \%$ do sexo masculino. A maioria das crianças $92,6 \%$ (93) recebeu a primeira dose de vacina contra o sarampo dos 9 aos 12 meses. De acordo com o número de doses de vacina recebida, observou-se que a maioria 73,2\% (74) recebeu três doses da vacina, 
enquanto $24,8 \%$ (25) receberam duas doses de vacina, e apenas $2 \%$ (2) receberam uma dose da vacina contra o sarampo. A idade com que foram colhidas as amostras de sangue das crianças variava de 4 a 6 anos. A maioria das crianças $82,2 \%$ (83), portanto tinha 5 anos na data da coleta de sangue.

Resultados da pesquisa de anticorpos contra o sarampo. Na distribuição dos resultados do teste de $\mathrm{IH}$, observou-se que $92,1 \%$ (93) dos soros testados demonstraram anticorpos contra o sarampo e que $7,9 \%$ (8) não demonstraram anticorpos.

Em relação ao sexo, em valores numéricos absolutos e relativos, houve discreto predomínio dos testes negativos 5,9\% (6) entre as crianças do sexo masculino, quando comparado com o sexo feminino $2 \%(2)$.
Com relação a idade em que a criança recebeu a primeira dose de vacina contra o sarampo, notouse que, somente uma criança, que recebeu a primeira dose com 15 meses, teve sorologia negativa. Enquanto que sete crianças entre as que foram vacinadas com primeira dose com idade igual ou inferior a 11 meses obtiveram resultados negativos pelo teste de $\mathrm{IH}$.

$\mathrm{Na}$ distribuição dos resultados de acordo com o número de doses recebidas de vacina contra o sarampo deve ser realçado que os testes negativos $7,9 \%$ (8) ocorreram entre as crianças que receberam mais que uma dose de vacina.

Foi observado nesta pesquisa, que das oito crianças que obtiveram resultados negativos pelo teste de $\mathrm{IH}$; duas mantiveram-se negativas quando retestadas pelo teste de ELISA. Portanto, os resultados mostraram que $98 \%$ das crianças vacinadas tinham anticorpos contra o sarampo no soro.

\section{DISCUSSÃO}

O sarampo, por sua morbidade e mortalidade, sempre foi um dos principais problemas de saúde pública no mundo inteiro. No Brasil, o histórico do sarampo foi marcado por várias epidemias, que ocorreram nos anos de 1980, 1984, 1986, 1990 e 1996/1997. No Estado de São Paulo, o número de casos confirmados laboratorialmente se reduz até 1995 , com apenas 8 casos no estado. Tem-se então que em 1996, após quase 10 anos de baixa incidência, o número de casos confirmados por laboratório aumentou para 22, e em 1997, o número de casos confirmados passou para $20.921^{32}$.

O esquema de vacinação recomendado pelo Programa Nacional de Imunização é de uma dose da vacina contra o sarampo aos 9 meses e outra aos 15 meses de idade. Crianças que receberam a primeira dose com um ano completo, ou mais, não deverão receber doses adicionais da vacina $^{12}$.

A última Norma Técnica do Programa de Imunização do Estado de São Paulo, regulamentou o esquema preconizado em 1992, que recomendava vacina contra o sarampo, na forma monovalente, aos nove meses, e aos 15 meses de idade, na forma trivalente, contra sarampo, rubéola e caxumba ${ }^{31}$.

A proteção contra o sarampo não tem sido relacionada somente com títulos de anticorpos, mas também, com outros fatores tais como, o intervalo entre a exposição e a vacinação ${ }^{7}$, idade de exposição $0^{8}$, intensidade da exposição ${ }^{13}$ e o sexo².

Wilkins et $\mathrm{al}^{36}$ observaram predomínio de falhas vacinais em crianças do sexo masculino, utilizando o teste de $\mathrm{IH}$. Em outro estudo ${ }^{6}$, que utilizou RNP, observou-se que as crianças do sexo masculino, pós vacina trivalente, tinha média geométrica do título de anticorpos contra o sarampo menor do que as crianças do sexo feminino. Portanto, essas observações estão de acordo com as do presente estudo.

Nas regiões em que a necessidade de utilização mais precoce da vacina contra o sarampo isto é, crianças com menos de um ano de idade, em virtude das pressões epidemiológicas, o calendário de vacinação inclui pelo menos duas doses de vacina.

Calendários que incluem duas doses de vacina em idades fixas para a administração, sendo a primeira antes do primeiro ano de vida, têm provado, serem efetivos e proveitosos no controle do sarampo.

Resultados de estudos epidemiológicos sugerem que as crianças imunizadas com menos de um ano de idade, que foram reimunizadas estão protegidas contra o desenvolvimento da doença clínica, quando expostas ao sarampo ${ }^{933}$. Um dos estudos mostrou que, durante epidemia, $35 \%$ das crianças que receberam uma dose de vacina, com idade igual ou menor que 12 meses, desenvolveram doença clínica. Por outro lado, 
quando a criança tinha recebido a segunda dose da vacina, este índice caiu para $2 \%{ }^{33}$.

O significado clínico de títulos de anticorpos menores em crianças revacinadas é incerto. Estudos mostram que muitas das crianças vacinadas falharam em desenvolver anticorpos pelo $\mathrm{IH}$, contra o vírus do sarampo, ou tem anticorpos detectados de forma transitória ${ }^{30} 33$. Entretanto, em um dos estudos, anticorpos neutralizantes foram encontrados no soro de todas as crianças, nas quais o teste de $\mathrm{IH}$ não foi capaz de detectar anticorpos contra o sarampo, após reimunização ${ }^{30}$.

Neste presente estudo, observou-se que $98,1 \%$ das crianças receberam duas ou três doses da vacina contra o sarampo, eram portanto, revacinadas.

Nos países em desenvolvimento, onde a mortalidade por sarampo é alta no primeiro ano de vida, a idade mais apropriada para aplicação da vacina ainda gera muita controvérsia, em virtude da inter-relação entre a pressão epidemiológica exercida por esta virose e a necessidade de atingir precocemente altas taxas de soroconversão nas crianças vacinadas ${ }^{14}$.

Dessa forma, é importante considerar para cada região do mundo qual é a menor idade em que a vacina contra o sarampo pode oferecer maior proteção às crianças ${ }^{9}$.

Neste estudo, as duas crianças que permaneceram com resultados negativos após o teste de IH e ELISA, receberam sua primeira dose de vacina contra o sarampo com idade inferior a onze meses.

Quando se testaram amostras pareadas para o diagnóstico de sarampo, o ELISA teve comportamento semelhante ao $\mathrm{IH}$, Imunofluorescência Indireta (IFA) e Fixação de Complemento $(F C)^{4}{ }^{1516}$. Entretanto, para o diagnóstico de sarampo, não são necessários testes altamentes sensíveis, porque os anticorpos elevam-se para níveis facilmente detectáveis pelos métodos disponíveis. Por outro lado, métodos de alta sensibilidade são importantes para a detecção de títulos baixos de anticorpos, como no caso de anticorpos maternos, ou quando é avaliada a taxa de soropositividade tempos após a vacinação. Situações estas em que os anticorpos caem para níveis não detectáveis, pelos métodos convencionais ${ }^{23}$. Em pesquisa realizada no Brasil a reação de $\mathrm{IH}$ se mostrou menos sensível que o ELISA ${ }^{19}$.
No presente estudo, foram utilizados os testes de IH e ELISA para avaliar a presença de anticorpos, em diferentes períodos, após aplicação da vacina contra o sarampo. A soropositividade encontrada pelo ELISA, nas amostras negativas pelo teste de $\mathrm{IH}$, mostrou sensibilidade superior.

O ELISA deve ser utilizado para testar grande número de amostras, é um método útil para pesquisas soroepidemiológicas de sarampo devido sua alta sensibilidade e reprodutibilidade, este teste deve ser utilizado para a avaliação da eficácia da vacina, anos após a vacinação. Nesse caso a RNP, não é a mais indicada, por ser um método complexo e dispendioso ${ }^{5}$.

Foi observado, nesta pesquisa, que oito crianças não tinham anticorpos contra o sarampo detectados pelo teste de IH. Dessas crianças, apenas duas mantiveram-se soronegativas quando foi utilizado o método de ELISA. Esse resultado significa que a resposta imune pode estar alterada, porque os títulos de anticorpos podem não ser detectados pelo método de $\mathrm{IH}$ e ELISA. Portanto, o índice de crianças sem detecção de anticorpos contra o sarampo neste estudo foi de $2 \%$.

Nas observações que avaliam os índices de soropositividade vários anos após a vacinação, o valor do declínio nos níveis de anticorpos é especialmente importante, porque as crianças soronegativas podem anteriormente terem tido anticorpos detectados.

É possível que crianças vacinadas com 12 meses de idade apresentem declínio mais rápido no nível de anticorpos do que as crianças vacinadas com idade maior ${ }^{21}$. Isto levaria à diferenças nos índices de presença de anticorpos tardios. Entretanto, não é certo ainda se a resposta primária seguida por um declínio e, mais tarde por soronegatividade reflete a perda da proteção contra a doença ${ }^{32}$. Em um estudo, várias crianças vacinadas que inicialmente soroconverteram e perderam a imunidade detectada, quando revacinadas tiveram rápido retorno anamnéstico de anticorpos ${ }^{1}$.

Sabe-se que o índice de falha de vacinação contra o sarampo é de 2 a $10 \%$, e é uma questão importante na epidemiologia do sarampo, pois a transmissão dessa doença poderia ser devida apenas às falhas da vacina ${ }^{11} 1822$. Entretanto, devem ser considerados os fatores de risco para as falhas na vacinação visando a proteção contra 
as doenças, entre outros os seguintes fatores: fatores inerentes a vacina; à sua distribuição e manipulação; à aplicação; aos fatores do hospedeiro; ao meio ambiente e por último fatores ligados a pesquisa.

Neste trabalho, torna-se importante ressaltar que não foi realizado estudo de soroconversão logo após a vacinação contra o sarampo, portanto, não foi possível afirmar que o índice de crianças que não tiveram anticorpos detectados dependeu de falha vacinal.

Em conclusão, os resultados desta pesquisa são semelhantes aos de outros estudos anteriores, realizados em populações com as mesmas características. Porém, não responde questões importantes que influenciam na proteção contra o sarampo, e ainda permanecem sem o completo esclarecimento, tais como: a idade ótima para a vacinação, duração da imunidade induzida pela vacina, a interferência do sexo na resposta à vacina e a utilização de programas de uma ou duas doses da vacina contra o sarampo. Nesse sentido, novas pesquisas soroepidemiológicas aleatórias, em grupos maiores de crianças, em condições de rotina, são necessárias para responder a estes questionamentos e melhor avaliar a eficácia da vacina contra o sarampo.

\section{REFERÊNCIAS BIBLIOGRÁFICAS}

1. Aaby P. Influence of cross-sex transmission on measles mortality in rural Senegal. The Lancet 340:388-391,1992.

2. Aaby P, Bukh J, Hoff G, Leerhoy J, Lisse IM, Mordhorst $\mathrm{CHM}$, Pedersen IR. High measles mortality in infancy related to intensity of exposure. Journal of Pediatrics 109:40-44, 1986.

3. Babbot FL, Gordon JE. Modern measles. American Journal the Medical Sciences 228:334-361, 1954.

4. Boteler, WL, Luipersbeck PM, Fuccillo DA, O'Beirne AJ. Enzyme-linked immunosorbent assay (ELISA) for measles antibody for detection of measles antibody. Journal of Clinical Microbiology 17:814-818, 1983

5. Brunell PA, Weigle K, Murphy MD, Shehad Z, Cobb E. Antibody response following measles-mumps-rubella vaccine under conditions of customary use. Journal of the American Medical Association 250:1409-1412, 1983.

6. Carson MM, Spady DW, Albrecht P, Beeler JA, Thipphawong J, Barreto L, Grimsrud KM, Pabst HF. Measles vaccination of infants in a well-vaccinated population. Pediatric Infectious Disease Journal 14:1722, 1995.

7. Centers for Disease Control. Measles prevention: recomendations of the Inmunnization Practices Advisory Committee (ACIP). Morbidity and Mortality Weekly Report 38:1-18, 1989.

8. Centers for Disease Control. Measles outbreak: Washington, 1989: Failure of delayed postexposure prophylaxis with vaccine. Morbidity and Mortality Weekly Report 39:617-619, 1990.

9. Cherry JD, Feigin RD, Lobes LA, Shackelford PG. Atypical measles in children previously immunized with attenuated measles virus vaccines. Pediatrics 50:712-717, 1972.

10. Enders JF. Measles virus. American Journal of Diseases of Children 103:282-87, 1962.

11. Frank JA, Orestein WA, Bart KJ, Bart SW, El-Tantawy N, Davis RM, Hinman AR. Major impediments to measles elimination. The modern epidemiology of an ancient disease American Journal of Diseases of Children 139:881-888, 1985.

12. Fundação Nacional de Saúde. Departamento de Operações. Coordenação de Imunizações e Auto Suficiência em Imunobiológicos. Programa Nacional de Imunização. Manual de Normas de Vacinação, Ministério da Saúde, Brasília, 1994.

13. Garenne M, Leroy O, Beau JP, Sene I. Efficacy of measles vaccines after controlling for exposure. American Journal of Epidemiology 138:182-194, 1993.

14. Hull HF, Willians PJ, Oldifield F. Measles mortality and efficacy in rural West Africa. The Lancet 1972-1975, 1983.

15. Kahane S, Goldstein V, Sarov I. Detection of IgG antibodies specific for measles virus by enzyme-linked immunosorbent assay (ELISA). Intervirology 12:39-46, 1979.

16. Kleiman MB, Blackcurn CKL, Zimmerman SE, Frenchm MLV. Comparison of enzyme-linked immunosorbent assay for acute measles with hemagglutination inhibition, complement fixation and fluorescent-antibody methods. Journal of Clinical Microbiology 14:147-152, 1981.

17. Krugman S, Giles JP, Friedman H. Studies on immunity to measles. The Journal of Pediatrics 66: 471-488, 1965.

18. Krugman S, Giles JP, Jacobs AM, Friedman H. Studies with a further attenuated live measles-virus vaccine. Pediatrics 31:919-928, 1963.

19. Lago JM, Marzagão MM, Curti SP, Souza VAF, Farhat CK, Carvalho ES. Viragem sorológica após vacinação contra o sarampo, realizada em crianças eutróficas e desnutridas, aos nove meses de idade. Jornal de Pediatria 72:311-318, 1996.

20. Lepow ML, Nankervis GA. Eight-year serologic evaluation of Edmonst live measles vaccine. The Journal of Pediatrics 75:407-411, 1969.

21. Linnemann CC Jr, Rotte TC, Schiff GM, Youtsey JL. A seroepidemiologic study of a measles epidemic in a highly 
immunized population. American Journal of Epidemiology 95:238-246, 1972.

22. Marks JS, Halpin TJ, Orenstein WA. Measles vaccine efficacy in children previously vaccinated at 12 months of age. Pediatrics 62:955-960, 1978.

23. Marks JS, Hayden GF, Orenstein WA. Methodologic issues in the evaluation of vaccine effectiveness. Measles at 12 vs 15 months. American Journal of Epidemiology 116:510-523, 1982.

24. Ministry of Health of Kenya and the World Health Organization. Measles immunity in the first year after birth and the optimum age for vaccination in Kenyan children. Bulletin of the World Health Organization 55:21-31, 1977.

25. Norrby E. Hemagglutination by measles virus. 4. A simple procedure for production of high potency antigen for hemagglutination-inhibition( $\mathrm{HI})$ tests. Proceedings of the Society for Experimental Biology and Medicine 111:814818, 1962.

26. Oliva OP, Chaves JRS, Loureiro MLP, Pereira LA, Homa A. Vacina CAM-70 contra sarampo produzida no Brasil. Avaliação de campo em crianças com 6 - 12 meses de idade. Boletim Epidemiológico 18:121-129, 1986.

27. Panum PL. Observations made during the epidemic of measles on the Faroe Islands in the year 1846. Medical Classics 3:829-886, 1939.

28. Rice GPA, Casali P, Oldstone MBA. A new solid-phase enzyme-linked immunosorbent assay for specific antibodies to measles virus. The Journal of Infectious Diseases 147:1055-1059, 1983.
29. Rosen L. Hemagglutination and hemagglutinationinhibition with measles virus. Virology 13:139-141, 1961.

30. Rosenthal SR, Clements CJ. Two-dose measles vaccination schedules. Bulletin of the World Health Organization 71:421-428, 1993.

31. Secretaria de Estado da Saúde. Norma Técnica do Programa de Imunização. São Paulo, 1994.

32. Secretaria de Estado da Saúde. Centro de Vigilância Epidemiológica "Prof. Alexandre Vranjac". A epidemia de sarampo do estado de São Paulo. Boletim Informativo, São Paulo, 50:3-6, 1998.

33. Shasby M, Shope TC, Downs H, Herrmann KL, Polkowoski J. Epidemic measles in a highly vaccinated population. The New England Journal of Medicine 296:589-600, 1977.

34. Wash JA. Selective primary health care, strategies for control of disease in the developing world. IV Measles. Reviews of Infectious Diseases 5:330-340, 1983.

35. Weigle KA, Murphy MD, Brunell P. A enzyme-linked immunosorbent assay for evaluation of immunity to measles virus. Journal of Clinical Microbiololgy 19:376379,1984

36. Wilkins J, Wehrle PF. Evidence for reinstatement of infants 12 to 14 months of age into routine measles immunization programs. American Journal of Diseases of Children 132:164-165, 1978. 